\title{
ПЕРСПЕКТИВЫ СОЗДАНИЯ ШКОЛЫ ТРАНСЦЕНДЕНТАЛЬНОЙ ПСИХОЛОГИИ В АРМЕНИИ
}

\author{
Нагдян Р. М. (Международный научно образовательный чентр \\ Академии наук, Ереван, Армения) \\ r.nagdyan@mail.ru

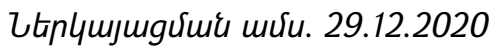

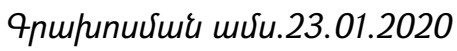

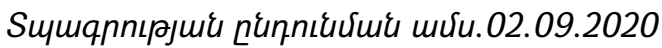

В статье подчеркивается отличие трансцендентального подхода к изучению психических явлений от методологий, господствующих в современной психологии. В этом контексте показывается возможность создания в Армении «своей» школы трансцендентальной психологии.

Ключевые слова: психика, методология, метафизика, трансцендентальная психология, психологическая школа.

Наука начинает наиболее интенсивно развиваться в том случае, если она актуализируется в русле определенной научной школы. Это обусловлено тем, что научное направление, определяющее содержание научной школы, способствует объединению единомышленников, многократно усиливающее их творческие возможности, возникновению многоаспектности изучемого предмета и созданию своего научного «лица» на международной арене психологической науки.

Возможность создания национальной или самостоятельной психологической школы в Армении появилась в конце 80-х годов минувшего столетия, которая однако не была реализована. Хотя, со всей уверенностью, можно сказать, что эта возможность реальна и сейчас. Речь идет о психологической концепции А.И. Миракяна, известная в настоящее время как «трансцендентальная психология». Попытаемся восстановить ход истории и выявить предпосылки возникновения новой парадигмы в психологии.

Датой основания трансцендентальной психологии восприятия можно считать 1987 год, когда в Психологическом институте Российской академии образования (Москва) была защищена докторская диссертация «Константность и полифункциональность восприятия» А.И. Миракяна [3]. В этой работе впервые была изложена методология афизикального (трансцендентального) подхода к изучению порождающего процесса восприятия и ее основные принципы. В чем же была необходимость перехода к новой парадигме? Традиционная психология восприятия формировалась на основе классической рациональности [10] и была направлена на решение вопроса: «Как человек воспринимает (отражает) окружающую действительность?». При такой, кажущейся естественной, 
постановке вопроса априори принимались следующие предпосылки исследования:

-Есть субъект и окружающий его мир. Они взаимодействуют.

-Мир и объекты, существующие в нем, не зависят от субъекта.

-Объекты обладают множеством свойств внутри каждой модальности восприятия, которые также независимы от воспринимающего их субъекта. Восприятие может внести свои искажения, но искажаются объективно и неазависимо существующие от человека свойства объектов.

Объект одновременно обладает множеством свойств, но невозможно исследовать все свойства объекта одновременно.

Приведенные выше предпосылки исследования процесса восприятия казались настолько естественными, что принимались как постулаты, не требующие теоретического анализа и эмпирических доказательств.

Постепенное формирование неклассической рациональности, привело, начиная с начала XX века по настоящее время, к осознанию необходимости введения в соотношение классической рациональности "объект-субъект» опосредующих звеньев для восстановления полноты, целостности и объективности исследования. Эти нововведения осуществлялись на самых разных уровнях исследования процесса восприятия - физическом (сюда могут быть включены приборы, ситуация исследования и окружающая среда), фризиологическом (фризиологические и химические процессы в нервной системе, нейронные сети и отдельные нейроны-датчики), психологическом (субъектные свойства личности). Однако при всем этом прогрессе в исследовании процесса восприятия крайние составляющие соотношения классической и неклассической рациональности, то есть «объект» и «субъект», сохраняются, поэтому вместе с ними сохраняются все четыре постулата, приведенные выше. В итоге, развитие психологии восприятия происходило таким образом, что невозможно было выявить универсальные принципы объяснения, объединяющие бесконечно разнообразную мозаику результатов исследований, а следствием оказалось то, что одна психологическая теория восприятия безуспешно заменялась другой. Сказанное относится не только к психологии восприятия, но и к психологии в целом. Именно поэтому причину такого состояния психологии В.М. Аллахвердов видел в том, что «все до сих пор созданные концепции психики содержат какой-то общий порок. Поэтому следует найти то общее, что содержится во всех психологических концепциях, и попробовать от него отказаться» [1, с. 11].

На пути к переосмыслению проблемы психического отражения А. И. Миракян (1987) исследовал причины, ограничивающие возможности его изучения, и пришел к выводу, что эти причины кроются в глубоко эмпирическом мышлении человека, функционирующем в пространстве продуктов (феноменов) психического отражения, через которые и определяется разделенность объекта 
и субъекта, свойственная классическому и неклассическому образу мышления. А такое мышление позволяет определить лишь характер отношений между психическими феноменами, но не позволяет проникнуть в неосознаваемый процесс их порождения и выявить его принципы.

Таким образом, возникает важная методологическая проблема преодоления ограниченности продуктного подхода, которая, в свою очередь, привела к необходимости проведения фрилософского анализа и построения такой картины мира, в котором реализуются принципы, определяющие возможности возникновения психической реальности. Такой анализ, как мы уже указывали в работе [15, с 11] начинается с вопроса «Как должен быть устроен мир, в котором (в ходе эволюции) возможно порождение психического?». Этот вопрос основан на нескольких постулатах:

1) материальный мир предшествует появлению психического;

2) мир (в целом) и принципы его развития не даны нам непосредственно (вывод - поэтому представления о них могут быть получены на основе философских рассуждений, относящихся к конкретному разделу фрилософрии метафизике, частью которой является метафизика бытия или онтология);

3) принципы порождения нового вечны и неизменны; относительны наши эмпирические представления о них (вывод - поэтому они, существовавшие в начале эволюции, действуют и сейчас, имплицитно многолико проявляясь и приобретая определенные характеристики в структурно-процессуальной организации фризических, биологических и фризиологических механизмов органов восприятия и в соответствующих им продуктах психического отражения).

Представленные выше системы постулатов коренным образом отличаюыся друг от друга, потому что описывают совершенно разные картины мира, разные реальности, поэтому созданные на их основе теоретические конструкции (методология, теории, концепции и т.д.), действительно, будут относится к разным парадигмам, обладающими разными методологическими ресурсами объяснения одних и тех же психологических явлений (что очень напоминает переход от механики классической ффизики к квантовой механике).

Таким образом, А.И. Миракян предлагает изучать принципы восприятия не через его феномены, данные нам в опыте, как это принято в современной психологии, а, совершив умозрительный переход в трансцендентальную, сверхчувственную, область процесса восприятия, используя априорные понятия, попробовать определить принципы порождающего процесса восприятия. Именно поэтому А.И. Миракян свое методологическое исследование начинает с представлений о новой, может быть, необычной, картины мира. Характеризуя эту картину мира, А.И. Миракян пишет: «по отношению к еще не свершившемуся акту отражения (еще нереализованной возможности отражения) принимаемое нами бесконечное многообразие материальных фрорм материи предстает в 
нерасчлененном, однородном виде, как некоторая гомогенность или глобальность. Понятие глобальности здесь вводится для того, чтобы дать представление о неотраженности и указать на ограниченность возможностей отражения в отношении того, что отражается. Объекты и их свойства как психические формы по логике прочесса отражения как фрормопорождения еще только должны становиться, образоваться, т.е. порождаться в прочессе отражения (выделено нами - Р.Н.), который можно трактовать как процесс упорядочивания глобальности, направленный в целом на самосохранение формы и адекватности функционирования живой системы в окружающей среде» [4 с. 39-40]. Из приведенной цитаты можно сделать несколько важных выводов, влияющих на наши представления о мире. Во-первых, в реальности, относящейся к трансцендентальной области «еще нереализованной возможности отражения», то есть в реальности, существующей до отражения, нет объектов с их свойствами, а есть материальные формы, составляющие нерасчлененную глобальность. Во-вторых, объекты и их свойства появляются как продукты процесса формопорождения, то есть уже как психические явления, показывая этим, что реальность, воспринятая и осознанная человеком, есть не что иное, как порожденные им же самим образы, ощущения, представления и т.д. Втретьих, заметим, что речь идет не об отражении, а о формопорождении, чем подчеркивается мысль о порождении нового, не имеющего сходства (аналога, копии, подобия и, тем более, тождества) с «отражаемым», снимая тем самым вопрос об адекватности отражения действительности.

Уже из сказанного становится ясно, что был предложен совершенно новый подход к методологии исследования психических явлений, не вписывающийся в рамки существующих методологий. Не вдаваясь в детали теоретических конструкций трансцендентального подхода, отметим, что его основные положения были подтверждены многочисленными экспериментами [15].

Работая и проживая в Москве, А.И. Миракян поддерживал постоянную связь с Арменией и армянскими психологами. В конце 80-х годов он приезжает в Ереван с целью основать свою школу, но, к сожалению, это ему не удается сделать и он возвращается в Москву, где и умирает в 1995 году.

Однако в Армении развитие концепции А.И. Миракяна было продолжено автором этих строк и Г.С. Есаяном. В итоге публикуются книги по трансцендентальной психологии [6], [7], [8], [11], [12], [13], [14]; в Ереване издается сборник статей армянских и российских психологов «Психология восприятия: трансцендентальная перспектива» [16]; защищается докторская диссертация «Метафизический подход к методологии исследования психического отражения реальности» [9], в которой впервые было обосновано, что фрилософрским фундаментом трансцендентальной психологии является метафизика в аристотелевском понимании. В дальнейшем под нашим руководством Г.С. Есаян 
защищает кандидатскую диссертацию «Вклад А.И. Миракяна в развитие концепции психического отражения» [2]. Таким образом можно считать, что теоретическая база для развития этого направления психологии в Армении создана. Однако многое предстоит еще сделать. Необходимо написать учебник по трансцендентальной психологии, организовать международные конференции по вопросам философии психологии, работать с научными кадрами, расширить возможности практического применения идей трансцендентальной психологии и т.д., что, конечно, требует больших организаторских усилий, финансовых вложений и, самое главное, привлечения в эту область молодых психологовэнтузиастов (и не только психологов), обладающих фрилософрскопсихологическим складом мышления. Одним из важных моментов развития трансцендентальной психологии является установление международных связей с заинтересованными психологическими сообществами.

\section{Литертура}

1. Аллахвердов В.М. Опыт теоретической психологии. СПб., 1993. - 198 с.

2. Есаян Г.С., Вклад А.И. Миракяна в развитие концепции психического отражения. Дисс. канд. пссихол. наук. Ер., 2016.

3. Миракян А.И. Константность и полифункциональность восприятия. Дисс. док. психол. наук. М., 1987.

4. Миракян А.И. Афизикальные принципы психического отражения и их моделирование//Принципы порождающего процесс восприятия (коллективная монография), под ред. А.И. Миракяна. М., 1992. С. 9-46.

5. Миракян А.И. Начала трансцендентальной психологии восприятия// Философрские исследования. 1995, № 2. С.77-94.

6. Нагдян Р.М. Психологический релятивизм реальности. Ер., Сарвард, 2007. - 90 с.

7. Нагдян Р.М. Психологический релятивизм реальности. Психология философии. Ер., НАИРИ, 2009. - 104 с.

8. Нагдян Р.М. Очерки метафизической психологии. Ер., НАИРИ, 2013. 190 с. (на арм. языке).

9. Нагдян Р.М. Метфизический подход к методологии исследования психического отражения реальности. Дисс. док. психол. наук. Ер., 2015.

10. Нагдян Р.М. Анализ соотношения классической и неклассической рациональности в психологии восприятия (психофизика, гештальтпсихология) // Ер.: Вестник РАУ, 3/2016. С. 105-118.

11. Нагдян Р.М. Загадка психики: трансцендентальная психология и метафизика. Ер., изд. Лусабац, 2017. - 424 с.

12. Нагдян Р.М. Методология трансцендентльной психологии. Ер., Лусабац, 2018. - 416 c. 
13. Нагдян Р.М. Трансцендентальная психология (Хрестоматия). Том 1. Ер., Лусабац, 2019. - 424 с.

14. Нагдян Р.М. Трансцендентальная психология (Хрестоматия). Том 2. Ер., Лусабац, 2019. - 424 с.

15. Принципы порождающего процесс восприятия (коллективная монография, под ред. А.И. Миракяна). М., 1992. - 220 с.

16. Психология восприятия: трансцендентальная перспектива / Сборник научных статей под ред. Р.М. Нагдяна и В.И. Панова. Ер.: НАИРИ, 2017. $344 \mathrm{c}$.

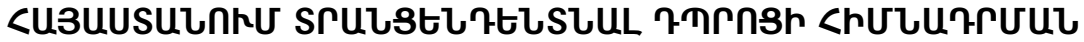 ctruluurutre}

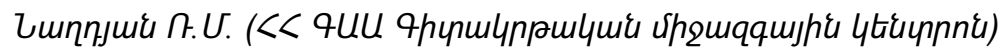

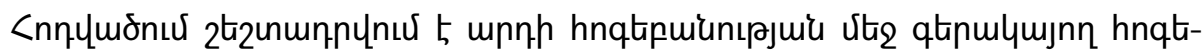

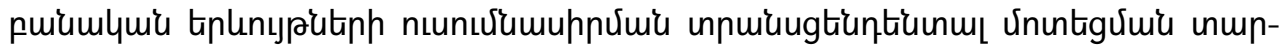

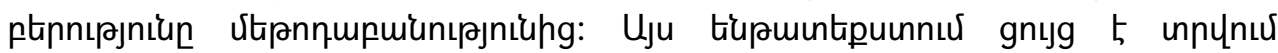

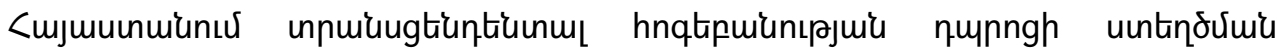

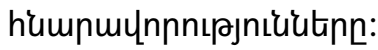

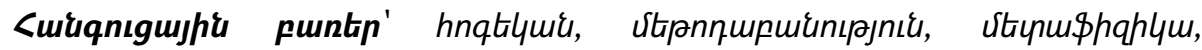

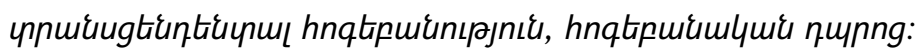

\section{ON THE POSSIBILITY OF CREATION OF THE ARMENIAN SCHOOL OF TRANSCENDENTAL PSYCHOLOGY}

Naghdyan R. M. (National Academy of Sciences of RA International Scientific and Educational Center, Yerevan, Armenia)

The article emphasizes the difference between the methodological approach of A.I. Mirakyan to the study of psychic phenomena from the methodologies that dominate in modern psychology. In this context, the possibility of creating of the "own" school of transcendental psychology in Armenia is shown.

Keywords: psyche, methodology, transcendental psychology, psychological school. 